\title{
Influence of humor expression on suicidal ideation among adolescents: mediating effects of depressive emotion and positive emotion
}

Chun-Yang Lee ${ }^{1}$, Yi-Chen Chiang ${ }^{2^{*+}} \mathbb{D}$, An Li ${ }^{2+}$, Xian Li ${ }^{2}$, Yao-Ting Wu ${ }^{3}$, Yu-Jung Lin ${ }^{4}$, Yuchen Zhao ${ }^{2}$ and Xiaoke Zhang ${ }^{2}$

\begin{abstract}
Background: The occurrence and degree of suicidal ideation during the past month in adolescents should be regarded seriously. Several studies have noted that humor expression style and depressive emotion may influence adolescents' suicidal ideation. However, there is insufficient evidence concerning whether positive emotion reduces such suicidal ideation in adolescents. In addition, the relationships among humor expression, depressive emotion, positive emotion and suicidal ideation remain to be confirmed. Therefore, in this study, we aimed to test the mediating roles of depressive emotion and positive emotion in the relationship between humor expression and recent adolescent's suicidal ideation.

Methods: A total of 1551 students in junior high school completed questionnaires. The collected data were analyzed using structural equation modeling (SEM) with LISREL 8.80 and Monte Carlo resampling with R.

Results: The results indicate that suicidal ideation in adolescents during the past month was related not only to humor expression but also to depressive emotion and positive emotion. The stronger the depressive emotion felt, the stronger the suicidal ideation; in contrast, the stronger the positive emotion, the weaker the suicidal ideation. Moreover, depressive emotion and positive emotion were found to mediate the relationship between humor expression and suicidal ideation; additionally, positive emotion was found to mediate the relationship between depressive emotion and suicidal ideation.

Conclusion: These results highlight that depressive emotion and positive emotion may mediate the influence of humor expression on suicidal ideation among adolescents, and positive emotion may mediate the influence of depressive emotion on suicidal ideation. More attention should be paid to decreasing adolescents' self-deprecating humor expression and depressive emotion, whereas more witty response humor expression and positive emotion should be encouraged to prevent their suicidal ideation.
\end{abstract}

Keywords: Adolescents, Humor expression, Depressive emotion, Positive emotion, Suicidal ideation, Mediating effects

\footnotetext{
* Correspondence: jyj@xmu.edu.cn

${ }^{+}$Yi-Chen Chiang and An Li are co-first authors.

${ }^{2}$ State Key Laboratory of Molecular Vaccinology and Molecular Diagnostics,

School of Public Health, Xiamen University, Xiamen, China

Full list of author information is available at the end of the article
}

(c) The Author(s). 2020 Open Access This article is licensed under a Creative Commons Attribution 4.0 International License, which permits use, sharing, adaptation, distribution and reproduction in any medium or format, as long as you give appropriate credit to the original author(s) and the source, provide a link to the Creative Commons licence, and indicate if changes were made. The images or other third party material in this article are included in the article's Creative Commons licence, unless indicated otherwise in a credit line to the material. If material is not included in the article's Creative Commons licence and your intended use is not permitted by statutory regulation or exceeds the permitted use, you will need to obtain permission directly from the copyright holder. To view a copy of this licence, visit http://creativecommons.org/licenses/by/4.0/. The Creative Commons Public Domain Dedication waiver (http://creativecommons.org/publicdomain/zero/1.0/) applies to the data made available in this article, unless otherwise stated in a credit line to the data. 


\section{Background}

Suicide is a major and serious public safety issue that can occur throughout life [1]. According to global data, approximately 800,000 people die by suicide every year. It has even become the second leading cause of death among 15-29-year-olds globally [1]. In China, suicide is the second leading cause of death among people aged 20-34 [2]. However, one of the most important risk factors for suicide is suicidal ideation [1]. One study has shown that subjects who experienced suicidal ideation at the age of 15 were nearly 12 times more likely than those that had not to have attempted suicide by the age of 30 [3].

Many factors affect suicidal ideation. In addition to the greatest risk factor, mental disorders such as depression [4-6] and anxiety [7], social skills [8] factors also influence it. Humorous expression is a social skills factor that affects suicidal ideation. A previous study has shown that both suicidal ideation and depressive emotion are negatively correlated with affiliative and self-enhancing humor styles. Among adolescents who use a more selfdefeating humor, however, the risk of committing suicide is higher [9].

Adolescence is a period of transition from childhood to adulthood; adolescents not only face a high degree of competitive pressure but also experience rapid physical and mental changes; as a result, their emotions are often unstable [10]. Research shows that teenagers between the ages of 12 and 16 can express humor and can use it to solve problems in daily life and social activities [11]. However, different types of humor expression may have different effects on mental health [12]. If one cannot effectively address and adjust one's humor style, it may lead to depression and other negative emotions and possibly even suicidal ideation. It is generally known that suicidal ideation at all ages is affected by depressive emotion [13]. Compared to adults, teenagers are more likely to be impulsive and emotionally unstable and therefore may be more likely to attempt suicide when they are very depressed or shortly after recovering from depression [14]. According to one survey, approximately $1 / 6$ of adolescents reported serious suicidal ideation in the past year [15]. Therefore, it is necessary to help teenagers adopt appropriate types of humorous expression to cope with life events.

\section{The importance of humor}

Humor expression are related to physical [16], mental $[12,17]$ and social health [18]. Among the related variables of mental health affected by humor expression, emotion [19] and suicidal ideation [9, 20] have gradually gained attention in recent years. Previous studies have suggested that humor can improve personal emotional distress and can be used as a buffer to cope with stress and adversity in daily life [21, 22]. Students with a strong sense of humor can look at problems more positively in the face of stress, making them feel less subjective stress, and they will use reevaluation and problem-solving strategies to help them reduce the threat of stress [23], thereby reducing the impact of stress events on depression. A study found that the link between neuroticism and emotional well-being is partly mediated by humor [24]. Individuals who more often use positive humor styles, such as affiliative and self-enhancing humor, have reduced melancholy tendencies and anxiety and a greater sense of happiness [25-28]. However, the more often individuals use negative humor styles such as aggressive humor and self-defeating humor, the greater their melancholy tendencies and anxiety will be; additionally, they will have lower psychological well-being [25]. Research has demonstrated that depression and anxiety are precursors of the desire to die by suicide and suicide attempts [29], while optimism is negatively correlated with suicidal ideation [30]. Perhaps this is why affiliative and self-enhancing humor styles are negatively correlated with suicidal risk; while self-defeating humor style is positively correlated with suicide risk. Individuals who naturally use self-defeating humor are at greater risk for suicidal ideation when experiencing feelings of thwarted belongingness. In contrast, an affiliative humor style may be a particularly important protective factor against suicidal ideation [9]. The cited research clearly suggests that affiliative humor can strengthen interpersonal relationships, ease social tensions, and even reduce the risk of suicidal ideation. To sum up, humor may influence suicidal ideation through depressive emotion or positive emotion. Chiang et al. found that selfdeprecating, other-devaluing, body language, and witty response humor were the four main humor expression types among adolescents [31]. When the student classroom climate favored self-deprecating/other-devaluing humor, and adolescents were more accepting of such humor, adolescents engaged more often in those humor types [32].

\section{The importance of depressive emotion and positive emotion}

Family and interpersonal stressors, negative life events, despair and depression are closely related to suicide behaviors in college students [33]. Some studies have shown that depression and suicidal ideation are highly structurally intertwined [34]. Among the risk factors of suicide, depression is important $[35,36]$. Furthermore, suicidal ideation is presumed to be an attempt to relieve or reduce stress [37]. Some teenagers report that they engage in self-harm and substance abuse to "stop bad feelings" or "to get relief" [37]. The finding that suicidal ideation is positively predicted by depression provides 
further evidence of the recognized link between depression and suicidal ideation [38].

Optimism is often closely associated with positive emotions, which are usually measured based on the use of words such as bold, certainty, hope, optimism, pride, superior, and win [39]. Studies have shown that depressive symptoms are associated with suicidal ideation [40], and the treatment of depression is an important and achievable clinical goal that reduces suicidal ideation [41, 42]. However, another study found that after controlling for the severity of despair and depression, students with higher levels of optimism also had lower levels of suicidal ideation [43]. This may be because optimistic individuals have more positive emotions, and consequently, suicidal ideation can be reduced. This finding suggests that actively promoting positive emotions may be a valuable strategy for suicide prevention [43].

\section{Current study and hypotheses}

This study aimed at investigating the correlations among humor expression, depressive emotion (DP), positive emotion (PO) and suicidal ideation (SUI) in adolescents. To this end, a research framework (Fig. 1) was constructed, a presupposition model (Fig. 2) was established, and hypotheses were proposed. We consider the self-deprecating (SD) and other-devaluing (OD) humor represent negative humor, while the body language (BL) and witty response (WR) humor represent positive humor. It was hypothesized that self-deprecating/other-devaluing humor would be positively correlated with suicidal ideation (H1). Next, it was hypothesized that body language/witty response humor would be negatively correlated with suicidal ideation (H2). Then, it was hypothesized that depressive emotion would mediate the relationship between humor expression and suicidal ideation (H3). Finally, it was hypothesized that positive emotion would mediate the relationship between humor expression and suicidal ideation (H4). To further examine the relationship between specific humor expression and suicidal ideation, we also established four subhypotheses: selfdeprecating humor would be positively correlated with suicidal ideation (H1.1); other-devaluing humor would be positively correlated with suicidal ideation (H1.2); body language humor would be negatively correlated with suicidal ideation (H2.1); witty response humor would be negatively correlated with suicidal ideation (H2.2).

\section{Methods}

Participants and data collection

In this study, five public junior high schools were randomly selected from northern, central, southern, and

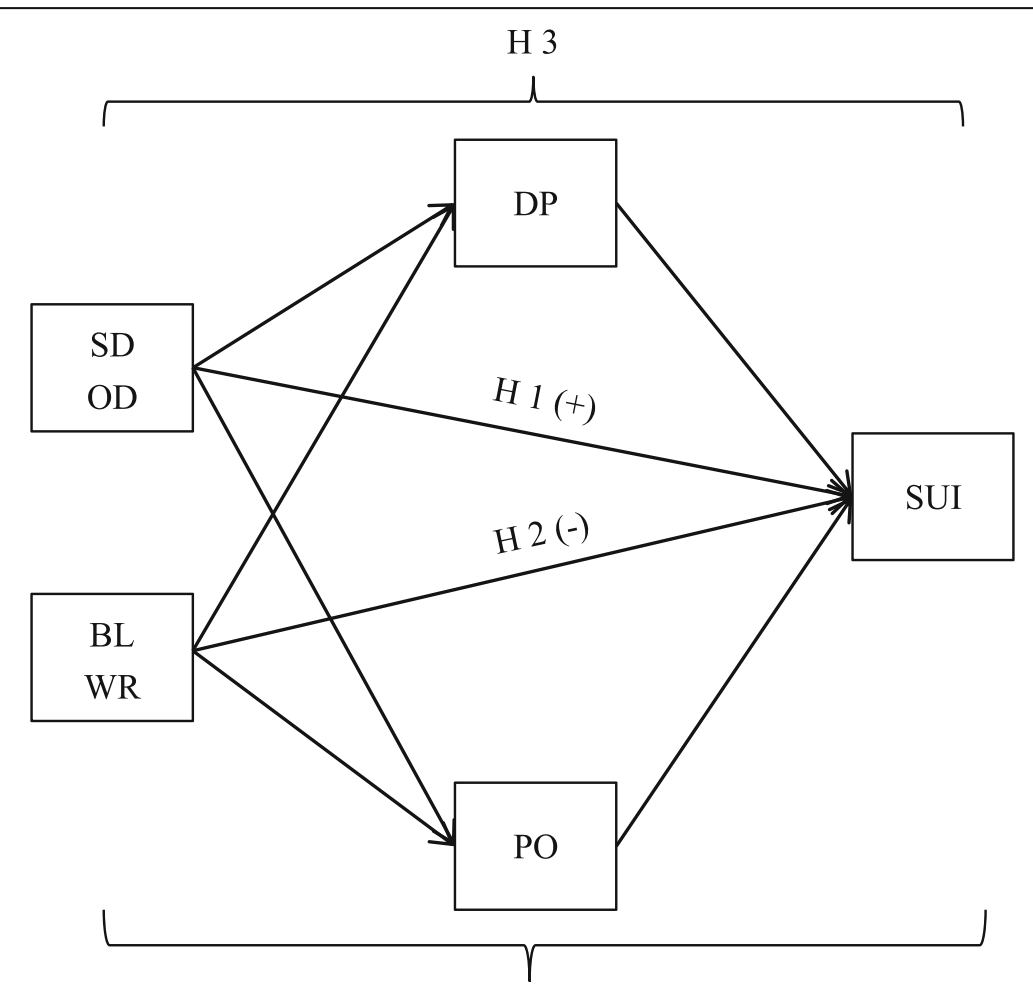

H 4

Fig. 1 Hypothesized model of the research framework. Note: SD: Self-deprecating, OD: Other-devaluing, BL: Body language, WR: Witty response, DP: Depressive emotion, PO: Positive emotion, SUI: Suicidal ideation 


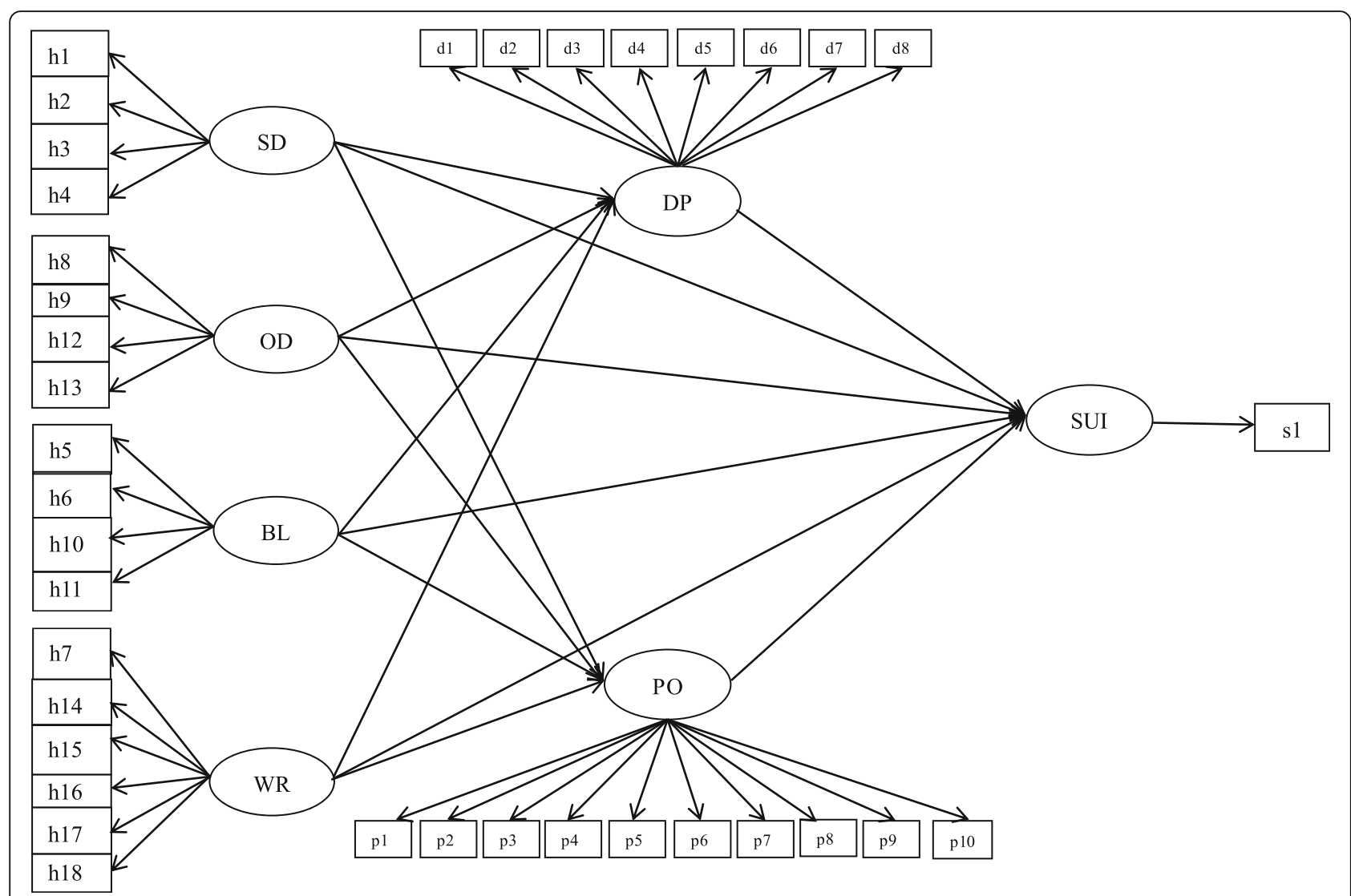

Fig. 2 Presupposition model of the relationships among adolescents' humor expression styles, emotions and suicidal ideation. Note: SD: Selfdeprecating, OD: Other-devaluing, BL: Body language, WR: Witty response, DP: Depressive emotion, PO: Positive emotion, SUI: Suicidal ideation

eastern Taiwan. One classroom of students from each grade (seventh, eighth, and ninth grade) was randomly selected from each school. Additional details regarding the sampling procedure have been described elsewhere [32]. Overall, 1639 students completed the questionnaire, for a response rate of $95.7 \%$. Excluding those with missing data, the valid sample totaled 1551.

In the data collection, 10 college undergraduate students or graduate students were recruited as interviewers and 10 senior interviewers as supervisors. After receiving training, they were dispatched to the sample schools to collect data. The supervisors first contacted the sample schools to obtain the schools' consent and to confirm when the questionnaire survey would be administered. On the day of the survey, the interviewer went to the selected class in each school and had the questionnaire completed by the entire class. Prior to the administration of the survey, the participants' parents provided informed consent. The participants completed the self-report questionnaires during class (in approximately $40 \mathrm{~min}$ ). This study was approved by the Institutional Review Board of the College of Public Health of National Taiwan University.

\section{Measures}

\section{Humor expression types}

We adopted the Taiwan Adolescent Humor Instruments (TAHI) method to measure the humor expression types; additional details regarding the 18-item scale have been described elsewhere [32]. The respondents were required to identify the extent to which they used these four different types of humor on a five-point rating scale ranging from 1 ("never") to 5 ("always"). The Cronbach's alphas for the self-deprecating, other-devaluing, body language, and witty response humor expression types were $0.86,0.85,0.86$, and 0.85 , respectively.

\section{Depressive emotion}

Adolescents self-reported their depressive emotion using the Child and Adolescent Behaviors in Long-Term Evolution (CABLE) Depression Scale. This scale was based on Kovacs's [44] Children's Depression Inventory (CDI) and Faulstich et al.'s [45] Center for Epidemiological Studies Depression Scale for Children (CES-DC) and is used as part of a 20-year cohort CABLE study in Taiwan every year. Depression was assessed by asking about the participant's emotional state over the last 2 weeks (on a scale from 1 to 5 , where $1=$ never; 2 =seldom; $3=$ 
sometimes; $4=$ very often; and $5=$ almost every day). The frequency of eight depressive emotions was evaluated: "Didn't feel like eating favorite foods", "Felt very sad", "Cried for no reason", "Found it hard to carry out tasks", "Felt frightened", "Didn't sleep well", "Lacked motivation", and "Felt depressed". The scores for each of the eight items were added together to give an overall total score ranging from 8 to 40 . Higher scores indicated that children reported more depressive emotions. In the present sample, the depression scale was shown to have a Cronbach's alpha of 0.88 .

\section{Positive emotion}

Adolescents self-reported their positive emotion using the Brief Measure of Positive Affect from the Positive and Negative Affect Scale (PANAS) [46]. Studies have shown PANAS is suitable for Chinese people [47]. We conducted a back-translation procedure for the scale and confirmed the proper wording for adolescents. Students were asked about their experience of ten positive emotions, such as "excited", "interested", and "enthusiastic", over the last 2 weeks and responded on a five-point scale (from $1=$ not at all to $5=$ very strong). The scores for each of the ten items were summed to give an overall total score ranging from 10 to 50 . Higher scores indicated that children reported more positive emotions. In the present sample, the scale was shown to have a Cronbach's alpha of 0.93 .

\section{Suicidal ideation}

Suicidal ideation was measured by asking participants "Did you ever think of ending your own life (not wanting to live or wanting to die) during the past month?" There were 5 possible responses ranging from "never" to "almost every day". "Have suicidal ideation during the past month" is a time category defined to identify recent high risk of suicide behavior. Therefore, we adopted "suicidal ideation during the past month" in this study to represent a high risk of future suicide behavior.

We conducted confirmatory factor analysis (CFA) for the instruments used to measure humor expression types (TAHI), depressive emotion (CABLE Depression Scale) and positive emotion (Brief Measure of PANAS). The TAHI goodness-of-fit index was as follows: (1) ChiSquare $/ \mathrm{df}=5.82$; (2) RMSEA $=0.056$; (3) GFI $=0.98$; (4) AGFI $=0.98 ; \quad$ (5) $\quad$ NNFI $=0.96 ; \quad$ (6) $\quad$ CFI $=0.96$. The goodness-of-fit index of the depressive emotion instrument was as follows: (1) Chi-Square/df $=9.33$; (2) RMSEA $=0.073 ; \quad$ (3) GFI $=0.99 ; \quad$ (4) $\quad$ AGFI $=0.98$; (5) $\mathrm{NNFI}=0.96$; (6) CFI $=0.97$. The goodness-of-fit index of the positive emotion instrument was as follows: (1) ChiSquare $/ \mathrm{df}=8.34$; (2) $\mathrm{RMSEA}=0.069$; (3) $\mathrm{GFI}=0.99$; (4) AGFI $=0.98 ; \quad$ （5） NNFI $=0.96 ; 6) \quad$ CFI $=0.97$. These outcomes indicate that all the instruments have good validity.

\section{Data analysis}

To test the hypotheses, structural equation modeling (SEM) was performed with LISREL 8.80 to analyze the relationships among humor expression, depressive emotion, positive emotion and suicidal ideation. In addition, the estimated total and indirect effects in the output file from LISREL and Monte Carlo resampling with $\mathrm{R}$ were adopted to confirm the significance of the indirect and total effects.

\section{Results}

\section{Participant characteristics}

The final sample included 802 boys (51.7\%) and 749 girls (48.3\%). The sex ratio was approximately 1:1. The distribution of participants across grades was similar: $30.1 \%$ of the students were in 7 th grade $(n=467), 34.3 \%$ were in 8 th grade $(n=532)$, and $35.6 \%$ were in 9 th grade $(n=$ $552)$. With respect to the area of residence, approximately a quarter of the participants were from each region. Of the different types of humor, witty response was the most common type used by students (mean = $3.25)$, followed by body language $($ mean $=2.60)$. Both the other-devaluing (mean $=1.88)$ and self-deprecating (mean $=1.85$ ) humor types were less common. In addition, the results revealed that the students' positive emotion (mean $=2.89$ ) was only slightly higher than the depressive emotion (mean $=2.06$ ), and $30.4 \%$ of the students had experienced suicidal ideation during the past month. The specific participant characteristics and descriptive statistics for the independent and dependent variables are presented in Tables 1 and 2 .

Table 1 Participant Characteristics

\begin{tabular}{lll}
\hline Variable & $\mathrm{n}$ & $\%$ \\
\hline Sex & & \\
boys & 802 & 51.7 \\
girls & 749 & 48.3 \\
Grade & & \\
7 & 467 & 30.1 \\
8 & 532 & 34.3 \\
9 & 552 & 35.6 \\
Region & & \\
northern & 363 & 23.4 \\
central & 431 & 27.8 \\
southern & 404 & 26.0 \\
eastern & 353 & 22.8 \\
\hline
\end{tabular}


Table 2 Descriptive statistics for the independent and dependent variables

\begin{tabular}{lllll}
\hline Variable & ME & SD & $n$ & $\%$ \\
\hline independent variables & & & & \\
Humor expression types & & & & \\
$\quad$ self-deprecating & 1.85 & 0.75 & & \\
$\quad$ other-devaluing & 1.88 & 0.74 & & \\
$\quad$ body language & 2.60 & 0.98 & & \\
$\quad$ witty response & 3.25 & 1.08 & & \\
Depressive emotion & 2.06 & 0.81 & & \\
Positive emotion & 2.89 & 0.84 & & \\
dependent variables & & & & \\
$\quad$ Suicidal ideation during the past month & & & \\
$\quad$ never & & & 1080 & 69.6 \\
$\quad$ seldom & & & 223 & 14.4 \\
$\quad$ sometimes to almost everyday & & & 248 & 16.0 \\
\hline Note: ME Mean, SD Standard deviation & & & &
\end{tabular}

The relationships among humor expression, depressive emotion, positive emotion and suicidal ideation

Based on the preset model, SEM was conducted to analyze the relationships among humor expression, depressive emotion, positive emotion and suicidal ideation. It was found that some of the $t$-values were less than
1.96 in model 1. Therefore, model 2 and model 3 were obtained by deleting $\mathrm{OD} \rightarrow \mathrm{PO}, \mathrm{OD} \rightarrow \mathrm{SUI}$, respectively, according to the smallest and nonsignificant $t$-values. In order to explore whether there is a better model, $\mathrm{BL} \rightarrow$ DP was deleted according to the minimum $t$-value to get model 4 (Fig. 3). Since the difference between the chisquare value of model 4 and model $1\left(\Delta \chi^{2}=5.82\right)$ is less than the cut-point of chi-square value $(7.81)$ by $\Delta \mathrm{df}=3$. Model 4 is our final model. The goodness-of-fit indices for each model are shown in Table 3.

The model diagram of the mediating effects (Fig. 3) clearly shows the direct effect among the relationships of study constructs (humor expression, depressive emotion, positive emotion and suicidal ideation). When humor expression directly acted on suicidal ideation, the effect of self-deprecating humor was significantly positive $(\beta=$ $0.10, p<.01)$; H1.1 was supported; however, the relationship between other-devaluing humor and suicidal ideation lacked statistical significance; $\mathrm{H} 1.2$ was not supported. As with self-deprecating humor, a significant positive effect of body language humor on suicidal ideation was found $(\beta=0.27, p<.001)$, contradicting H2.1. In contrast, the effect of witty response humor expression on suicidal ideation was significantly negative $(\beta=-0.30$, $p<.001)$; H2.2 was supported. To sum up, H1 and H2 were partially supported. The overall direct effect,

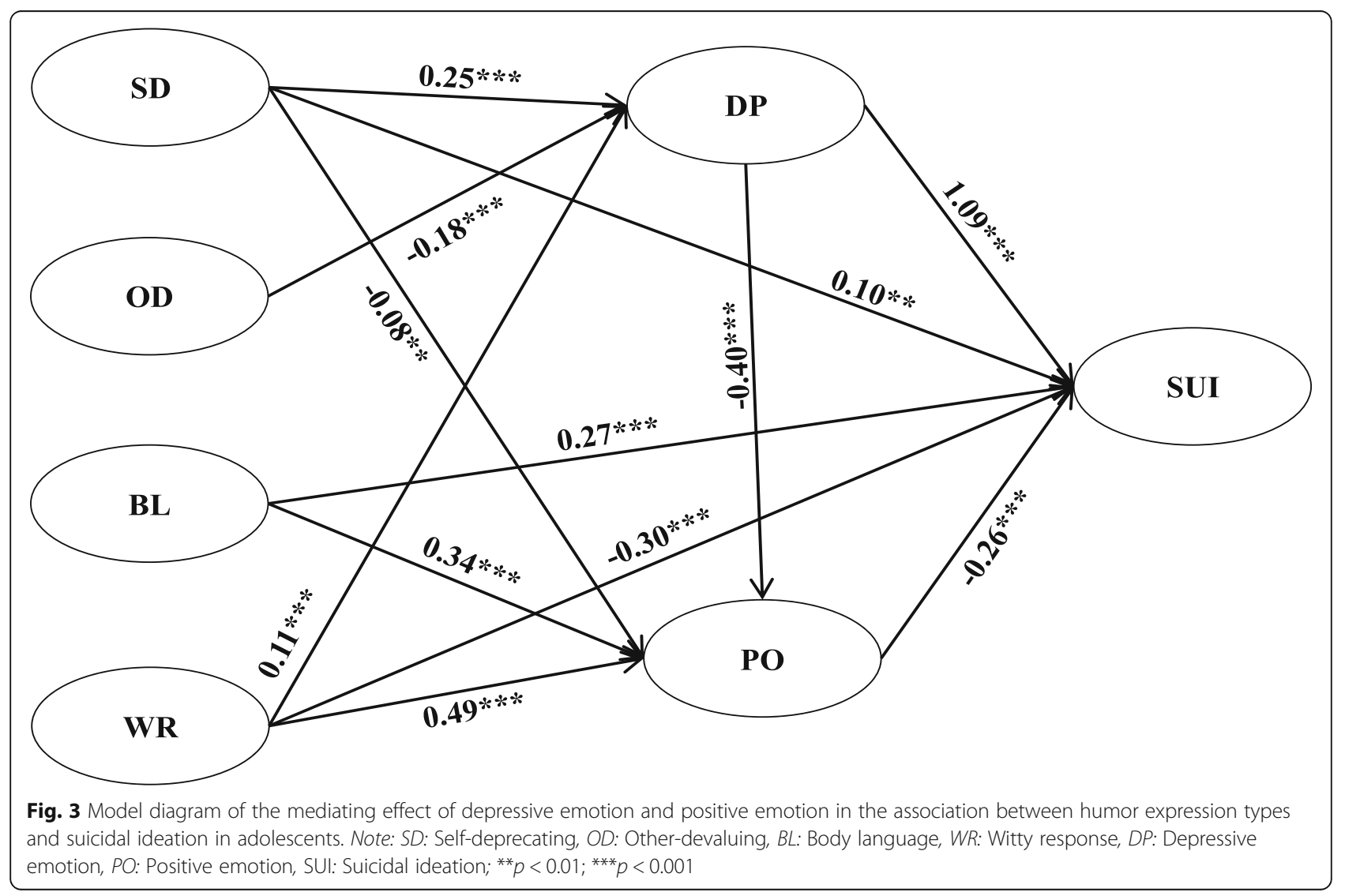


Table 3 Comparison of the measurement models

\begin{tabular}{lllllllllll}
\hline Model & $\mathrm{X}^{2}$ & $\mathrm{df}$ & $\mathrm{X}^{2} / \mathrm{df}$ & $\mathrm{RMSEA}$ & $\mathrm{NFI}$ & $\mathrm{GFI}$ & $\mathrm{NNFI}(\mathrm{TLI})$ & $\mathrm{CFI}$ & IFI & CN \\
\hline Model 1 & 3049.77 & 609 & 5.01 & 0.051 & 0.96 & 0.98 & 0.97 & 0.97 & 0.97 & 353.27 \\
Model 2 & 3049.92 & 610 & 5.00 & 0.051 & 0.96 & 0.98 & 0.97 & 0.97 & 0.97 & 353.79 \\
Model 3 & 3051.00 & 611 & 4.99 & 0.051 & 0.96 & 0.98 & 0.97 & 0.97 & 0.97 & 354.21 \\
Model 4 & 3055.59 & 612 & 4.99 & 0.051 & 0.96 & 0.98 & 0.97 & 0.97 & 0.97 & 354.22 \\
\hline
\end{tabular}

indirect effect and total effect of the humor expression on adolescent suicidal ideation were calculated by LISR EL and are shown in Table 4 (the diagram and calculation formula are provided in Fig. 4). The table clearly indicates that the indirect effect of self-deprecating humor on suicidal ideation was $0.319\left[0.25^{*} 1.09+0.25^{*}(-\right.$ $\left.0.4)^{*}(-0.26)+(-0.08)^{*}(-0.26)\right]$; the indirect effect of other-devaluing humor on suicidal ideation was -0.215 $\left[-0.18^{*} 1.09+(-0.18)^{*}(-0.4)^{*}(-0.26)\right]$; the indirect effect of body language humor on suicidal ideation was -0.088 $[0.34 *(-0.26)]$; and the indirect effect of witty response humor on suicidal ideation was $0.004\left[0.11^{*} 1.09+\right.$ $0.11 *(-0.4) *(-0.26)+0.49 *(-0.26)]$. In summary, depressive emotion mediated the relationship between selfdeprecating/other-devaluing/witty response and suicidal ideation; positive emotion mediated the relationship between self-deprecating/body language/witty response and suicidal ideation. Thus, for the most part, $\mathrm{H} 3$ and H4 have been preliminarily supported.

To further verify the mediation hypotheses (H3 and H4), Monte Carlo resampling was used to construct the opportune confidence intervals [48, 49]. More precisely, we used a program written in $\mathrm{R}$ to construct $95 \%$ confidence intervals for the indirect effects based on 20,000 resamples [48, 49]. The tests results for indirect effects in model 4 (our final model) using Monte Carlo resampling are shown in Table 5. The results reveal that the $95 \%$ confidence interval for all indirect effect in model 4 did not include zero. Therefore, $\mathrm{H} 3$ and $\mathrm{H} 4$ were partially supported.

In addition, we tried to include the three control variables (i.e., sex, grade, 3 dummy variables of area) in the final SEM model. However, no model was positive

Table 4 Descriptive statistics for the direct effect, indirect effect and total effect of the humor expression types on adolescent suicidal ideation

\begin{tabular}{llll}
\hline Path & $\mathrm{DE}$ & $\mathrm{IE}$ & $\mathrm{TE}$ \\
\hline $\mathrm{SD} \rightarrow \mathrm{SUI}$ & $0.100^{* *}$ & $0.319^{* * *}$ & $0.419^{* * *}$ \\
$\mathrm{OD} \rightarrow \mathrm{SUI}$ & - & $-0.215^{* * *}$ & $-0.215^{* * *}$ \\
$\mathrm{BL} \rightarrow \mathrm{SUI}$ & $0.270^{* * *}$ & $-0.088^{* * *}$ & $0.182^{* * *}$ \\
$\mathrm{WR} \rightarrow$ SUI & $-0.300^{* * *}$ & 0.004 & $-0.296^{* * *}$ \\
\hline
\end{tabular}

Note: SD Self-deprecating, $O D$ Other-devaluing, $B L$ Body language, WR Witty response, $D P$ Depressive emotion, $P O$ Positive emotion, SUI Suicidal ideation, $D E$ Direct effect, IE Indirect effect, TE Total effect; ${ }^{* *} p<.01,{ }^{* * *} p<.001$ definite. To determine the influence of these control variables on suicidal ideation, we also ran SEM while controlling for the three variables using lavann with $\mathrm{R}$. However, the results provided by lavann showed that the model could not be identified and that it could not invert the information matrix needed for robustness test statistics. Furthermore, we also used the proportional odds logit model to analyze control variables, independent variables and mediating variables with SAS software. The results showed that all control variables in the model had no significant relationship with the dependent variable. Hence the effect of the three control variables on the suicidal ideation is trivial.

\section{Discussion}

The purpose of this study was to examine the mediating roles of depressive and positive mood in the relationship between humor expression and suicidal ideation in adolescents. Therefore, in addition to predicting the simple relationships among humor expression, depressive emotion, positive emotion and suicidal ideation, it was also hypothesized that depressive emotion and positive emotion would play an important role in explaining the relationship between humor expression and suicidal ideation. Studies have shown that humor expression is an important factor related to suicidal ideation; however, research has not yet examined whether depressive emotion and positive emotion can further explain this relationship. As in previous research, the results of this study revealed a relationship between humor expression and suicidal ideation as well as relationships between humor expression and depressive emotion/positive emotion. Furthermore, the current findings extend previous research by indicating that depressive emotion and positive emotion mediate the relationship between humor expression and suicidal ideation; positive emotion may be another important mediating factor between depressive emotion and suicidal ideation.

\section{The relationships among humor expression, depressive emotion, positive emotion and suicidal ideation}

This study found that if adolescents constantly use the self-deprecation to express humor, they are likely to experience more depressive emotion $[25,50,51]$ and suicidal ideation [51]. This result is consistent with research findings from other countries. We further 


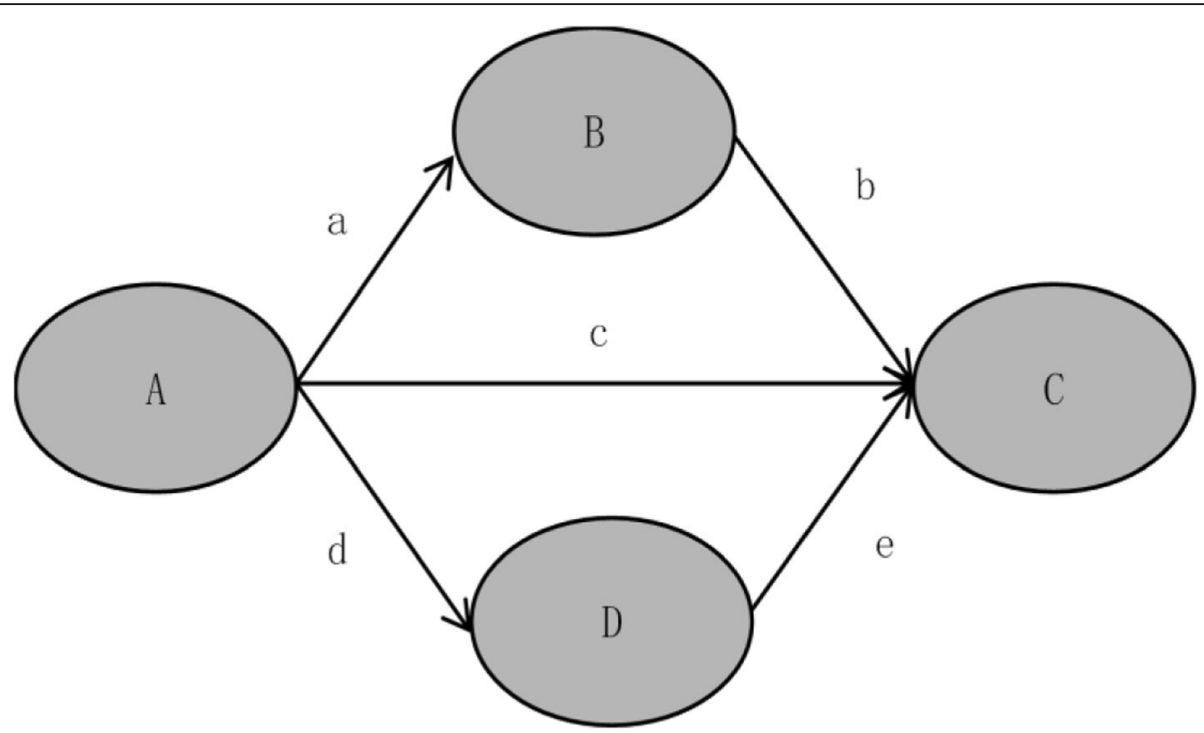

Fig. 4 Schematic calculation diagram of direct effect, indirect effect, and total effect. The indirect effect (IE) of $A$ on $C$ is calculated by a *b $+d *$ e; The direct effect (DE) of $A$ on $C$ is $C$; The total effect (TE) of $A$ on $C$ is calculated by IE + DE

found that teenagers had less positive emotion if they liked to use self-deprecating humor. However, adolescents who often use other-devaluing humor are less likely to experience depressive emotion $[25,26]$, perhaps because the object of belittlement is someone else rather than themselves. It is worth mentioning that if body language is often used to express humor, suicidal ideation and positive emotion may coexist. This result runs counter to $\mathrm{H} 2.1$ and $\mathrm{H} 1$ and may be due to the effect of adolescent hormones and the obvious increase in academic pressure in junior high school. Adolescents may tend to use reverse thinking combined with exaggerated body movements to express humor. In a similar way, Americans tend to deliberately ignore their personal sufferings through "black humor", reflect on the awkward circumstances and encounters they face, undermine an atmosphere of terror with humor, and reveal the absurdity of the world through laughter. This style of humor showcases gloom and despair but is also a release from it that

Table 5 Tests of Indirect Effects of the Hypothesized Model by Monte Carlo approach of resampling

\begin{tabular}{ll}
\hline Path & $95 \%$ confidence interval \\
\hline $\mathrm{SD} \rightarrow \mathrm{DP} \rightarrow \mathrm{SUI}$ & {$[0.218,0.327]$} \\
$\mathrm{SD} \rightarrow \mathrm{PO} \rightarrow \mathrm{SUI}$ & {$[0.007,0.036]$} \\
$\mathrm{OD} \rightarrow \mathrm{DP} \rightarrow \mathrm{SUI}$ & {$[-0.248,-0.145]$} \\
$\mathrm{BL} \rightarrow \mathrm{PO} \rightarrow \mathrm{SUI}$ & {$[-0.129,-0.053]$} \\
$\mathrm{WR} \rightarrow \mathrm{PO} \rightarrow \mathrm{SUI}$ & {$[-0.171,-0.087]$} \\
$\mathrm{WR} \rightarrow \mathrm{DP} \rightarrow \mathrm{SUI}$ & {$[0.059,0.183]$} \\
$\mathrm{DP} \rightarrow \mathrm{PO} \rightarrow \mathrm{SUI}$ & {$[0.081,0.129]$}
\end{tabular}

Note: $S D$ Self-deprecating, $O D$ Other-devaluing, $B L$ Body language, $W R$ Witty response, $D P$ Depressive emotion, $P O$ Positive emotion, SUI Suicidal ideation allows one to laugh at the human experience [52]. As a result, body language humor is likely to reflect suicidal ideation and the derivation of positive emotion from despair at the same time. This study originally expected that witty response humor would have a protective effect on emotion and suicidal ideation. However, the findings showed that although witty response humor was positively correlated with positive emotion and was negatively correlated with suicidal ideation, depressive emotion was still present. Perhaps, as the Mio [53] study shows, if witty response humor is used properly, it may be a helpful expression of humor, but if it is not used properly, it may have a negative effect. Therefore, the results of this study contradict the hypothesis, but whether this is because witty response humor is a more advanced form of humor requires further study.

\section{Mediating effects of depressive emotion and positive emotion on the effect of humor expression on suicidal ideation among adolescents}

This research found that depressive emotion and positive emotion play important mediating roles in the effect of humor expression type on adolescent suicidal ideation. The adolescents who tended to use self-deprecating humor expression experienced more depressive emotions and less positive mood and had a higher degree of suicidal ideation. The indirect effect was greater than the direct effect (more than threefold), indicating that the mediating effects of depressive emotion and positive emotion were obvious and may have strengthened the influence of adolescents' suicidal ideation. However, adolescents' use of other-devaluing humor was not directly related to suicidal ideation. Only an indirect effect 
existed, which means that students who relied on otherdevaluing humor experienced a lower degree of suicidal ideation with the mediating effect of depressive emotion and a positive effect. Superiority theory takes humor as arising from a feeling of superiority over others (e.g. ethnic jokes) or above one's previous position [54]. A subset of this view is disparagement theory, which holds that humor includes 'humorous material in which one protagonist disparages or aggresses against another one' [55]. Humor and laughter are also considered to be useful mechanisms for easing tension in the body and protecting the body and spirit [56]. However, body language humor had a greater direct effect on adolescents' suicidal ideation than an indirect effect through their positive emotion. In other words, adolescents who tended to use body language to express humor may have experienced less suicidal ideation in the presence of positive emotion. The indirect protective effect of positive emotion and direct protective effect of witty response humor on suicidal ideation was greater than the negative indirect effect of depressive emotion. Thus, the use of witty response humor had a negative relationship with suicidal ideation.

\section{Positive emotion may be another important mediating} factor between depressive emotion and suicidal ideation In the process of modifying the model goodness-of-fit indices according to the modification indices recommended by the LISREL software, it was found that depressive emotion affected the suicidal ideation of adolescents through positive emotion. This finding suggests that positive emotion may be another important mediator between depressive emotion and suicidal ideation. This finding was further confirmed by Monte Carlo resampling. Perhaps adolescents who use negative humor tend to have negative thoughts and are less likely to have positive emotion after they develop depression, which can easily result in suicidal ideation. Positive humor has the opposite effect.

\section{Limitations and recommendations}

This study was used SEM and the Monte Carlo resampling to reveal the mediating role of depressive emotion and positive emotion in the relationship between humor expression and suicidal ideation in adolescents. However, the study's limitations should be considered. First, this analysis is based on secondary data. We could only use single item of screening the suicidal ideation in students. However, the single item used to measure suicidal ideation in teenagers has been applied elsewhere, e.g., in a WHO international survey for school-aged children (Health behavior in school-aged children study, HBSC) [57], the American CDC Youth Risk Behavior Surveillance System (YRBSS) [58], and the 20-year cohort study
"Child and Adolescent Behaviors in Long-term Evolution (CABLE) Project" in Taiwan. Addition details regarding CABLE are provided in an article we published in BMC Public Health [59]. Second, the data source used a cross-sectional research design. Therefore, the inference of causality is more conservative. As in many humor studies, it is difficult to clearly establish the time sequence of humorous expression, emotion and suicidal ideation, particularly because of the commonly used measurement duration. Third, the questionnaires used in the study were self-reported, and thus, the participants' responses may reflect recall bias. Fortunately, our data were drawn from a representative sample from across Taiwan with a response rate of $95.7 \%$. The findings with decent goodness-of-fit indices are worthy of scholarly attention. Furthermore, it was also suggested to test measurement invariance of our research constructs across subgroups (e.g., region and sex) of respondents.

Despite these limitations, this study provides novel information on which several recommendations for future research can be based. For example, the study suggests several strategies that can be considered in intervention programs. First, one should popularize knowledge of different humorous expression styles among adolescents to enhance their awareness of the benefits and harms of the different styles and reduce the use of harmful humorous expression styles that increase suicidal ideation. Second, one should improve the understanding of psychological guidance in adolescents and encourage them to seek help from school mental health professionals to relieve depressive and other negative emotions effectively and in a timely manner. School mental health professionals are best equipped to lead school-based suicide prevention efforts because they have training and background both in mental health and social, emotional, and behavioral strategies, as well as in multilevel systems of support [60]. Specifically, adolescents should be encouraged to help those around them create a positive and healthy state of mind. As a result, the risk of suicidal ideation and even suicidal behavior could be noticeably reduced. Third, therapists could use positive psychology interventions (PPI) to mitigate depressive emotion and to cultivate positive affect, optimism, and other positive psychological factors [61], thus reducing the risk of suicide. The results of this study confirm that in addition to depressive emotion acting as mediator between humor expression and suicidal ideation, positive emotion also plays a mediation role between humor expression and suicidal ideation. Research has confirmed that PPI effectively improves subjective and psychological wellbeing and reduces depressive symptoms [62]. Furthermore, there were no significant differences between internet PPI and internet cognitive behavioural therapy 
(iCBT) at the 6-month follow-up for depression or for happiness [63]. Both interventions are effective in reducing depression and increasing happiness. Therefore, PPI should be considered an effective way to mitigate depressive emotion and reduce suicidal ideation. Fourth, one should make full use of the clear distinguishability of different types of humorous expression to encourage people to pay close attention to and help adolescents who use negative humor (particularly self-deprecating humor) to form a protective net and reduce the possibility of adverse consequences.

\section{Conclusions}

In conclusion, the current study reports the mediating role of depressive emotion and positive emotion in the relationship between humor expression and suicidal ideation as well as the mediating role of positive emotion in the relationship between depressive emotion and suicidal ideation among adolescents. The results of this study emphasize the importance of depression and positive emotion in adolescent humor expression and suicidal ideation. It is necessary to properly evaluate and intervene in adolescents' depressive emotion and promote their positive emotion.

\section{Abbreviations}

SEM: Structural Equation Modeling; DP: Depressive Emotion; PO: Positive Emotion; SUI: Suicidal Ideation; SD: Self-Deprecating; OD: Other-Devaluing; BL: Body Language; WR: Witty Response; TAHI: Taiwan Adolescent Humor Instruments; CABLE: Child and Adolescent Behaviors in Long-term Evolution; CDI: Children's Depression Inventory; CES-DC: Center for Epidemiological Studies Depression Scale for Children; PANAS: Positive and Negative Affect Scales; CFA: Confirmatory Factor Analysis; DE: Direct Effect; IE: Indirect Effect; TE: Total Effect; HBSC: Health Behavior in School-aged Children Study; YRBSS: Youth Risk Behavior Surveillance System; PPI: Positive Psychology Interventions; iCBT: Internet Cognitive Behavioural Therapy

\section{Acknowledgements \\ The authors would like to acknowledge all research assistants and investigators for their dedicated assistance in the data collection. Miss Shengnan Lin and Miss Meijie Chu are acknowledged for helpful comments on our earlier draft or revised manuscript. We also appreciated the assistance from PAN-ASIA Management Consultants Corporation. We would especially like to thank our participants in the study for their time and willingness to participate.}

\section{Authors' contributions}

CYL, YCC and AL (the first authors) carried out the analysis and conducted the manuscript writing, and also have made major modifications and improvements to the article. XL, YTW, YJL, YCZ, XKZ reviewed and further edited the article. YCC provides funding acquisition during the research process. All the authors have read and approved the final version.

\section{Funding}

The project was supported by the Natural Science Foundation of Fujian Province of China (No. 2018 J01129), and Scientific Research Grant of Fujian Province of China (No. Z0230104). The sponsors of the project had no role in the study design, data collection, data analysis, data interpretation and in writing the manuscript.

\section{Availability of data and materials}

The datasets used and/or analyzed during the current study are available from the corresponding author on reasonable request.

\section{Ethics approval and consent to participate}

This study was approved by the Institutional Review Board (IRB) of the College of Public Health of National Taiwan University. All students' parents consent for participation will be provided in writing before survey.

\section{Consent for publication}

Not Applicable.

\section{Competing interests}

The authors declare that they have no competing interests.

\section{Author details}

${ }^{1}$ School of International Business, Xiamen University Tan Kah Kee College, Zhangzhou, China. ${ }^{2}$ State Key Laboratory of Molecular Vaccinology and Molecular Diagnostics, School of Public Health, Xiamen University, Xiamen, China. ${ }^{3}$ Health Bureau, Taichung City Government, Taichung, China. ${ }^{4}$ Department of Public Health, Chung Shan Medical University, Taichung, China.

Received: 18 January 2020 Accepted: 12 August 2020

Published online: 26 August 2020

\section{References}

1. World Health Organization. Suicide. https://www.who.int/news-room/factsheets/detail/suicide. Accessed 2 Sept 2019.

2. Wang CW, Chan CLW, Yip PSF. Suicide rates in China from 2002 to 2011: an update. Soc Psychiatry Psychiatr Epidemiol. 2014;49(6):929-41. https://doi. org/10.1007/s00127-013-0789-5.

3. Reinherz HZ, Tanner JL, Berger SR, Beardslee WR, Fitzmaurice GM. Adolescent suicidal ideation as predictive of psychopathology, suicidal behavior, and compromised functioning at age 30. Am J Psychiatr. 2006; 163(7):1226-32. https://doi.org/10.1176/ajp.2006.163.7.1226.

4. Cavanagh JTO, Carson AJ, Sharpe M, Lawrie SM. Psychological autopsy studies of suicide: a systematic review. Psychol Med. 2003;33(3):395-405. https://doi.org/10.1017/s0033291702006943.

5. Dahlin M, Joneborg N, Runeson B. Stress and depression among medical students: a cross-sectional study. Med Educ. 2005;39(6):594-604. https://doi. org/10.1111/j.1365-2929.2005.02176.x.

6. Dyrbye LN, Thomas MR, Massie FS, Power DV, Eacker A, Harper W, et al. Burnout and suicidal ideation among U.S. medical students. Ann Intern Med. 2008;149(5):334-W70. https://doi.org/10.7326/0003-4819-149-5200809020-00008

7. Choi HY, Kim SI, Yun KW, Kim YC, Lim WJ, Kim EJ, Ryoo JH. A study on correlation between anxiety symptoms and suicidal ideation. Psychiatry Investig. 2011;8(4):320-6. https://doi.org/10.4306/pi.2011.8.4.320.

8. Kwok SYCL, Shek DTL. Cognitive, emotive, and cognitive-behavioral correlates of suicidal ideation among Chinese adolescents in Hong Kong. Sci World J. 2010:10:366-79. https://doi.org/10.1100/tsw.2010.42.

9. Tucker RP, Wingate LR, O'Keefe VM, Slish ML, Judah MR, Rhoades-Kerswill S. The moderating effect of humor style on the relationship between interpersonal predictors of suicide and suicidal ideation. Personal Individ Differ. 2013;54(5):610-5. https://doi.org/10.1016/j.paid.2012.11.023.

10. Yen LL, Chiang YC, Chiu YC, Cheng CC, Wu WC, Yang HJ. The concept of humor and performance patterns among junior high school students: results of focus group discussions. Taiwan J Public Health. 2008;27:519-29. [in Chinese].

11. Führ M. Some aspects of form and function of humor in adolescence. Humor. 2001;14(1):25-36. https://doi.org/10.1515/humr.14.1.25.

12. Chen GH, Martin RA. A comparison of humor styles, coping humor, and mental health between Chinese and Canadian university students. Humor. 2007;20(3):215-34. https://doi.org/10.1515/humor.2007.011.

13. Rohde P, Lewinsohn PM, Klein DN, Seeley JR, Gau JM. Key characteristics of major depressive disorder occurring in childhood, adolescence, emerging adulthood, and adulthood. Clin Psychol Sci. 2012; (1):41-53. https://doi.org/ 10.1177/2167702612457599.

14. Lewis AJ, Bertino MD, Bailey CM, Skewes J, Lubman DI, Toumbourou JW. Depression and suicidal behavior in adolescents: a multi-informant and multi-methods approach to diagnostic classification. Front Psychol. 2014;5: 766. https://doi.org/10.3389/fpsyg.2014.00766. 
15. Centers for Disease Control and Prevention. Web-based Injury Statistics Query and Reporting System (WISQARS), 2017. http://webappa.cdc.gov/cgibin/broker.exe.

16. Martin RA. Sense of humor and physical health: theoretical issues, recent findings, and future directions. Humor. 2004;17(1-2):1-19. https://doi.org/10. 1515/humr.2004.005.

17. Tagalidou N, Distlberger E, Loderer V, Laireiter AR. Efficacy and feasibility of a humor training for people suffering from depression, anxiety, and adjustment disorder: a randomized controlled trial. BMC Psychiatry. 2019; 19(1):93. https://doi.org/10.1186/s12888-019-2075-x.

18. Lockwood NL, Yoshimura SM. The heart of the matter: the effects of humor on well-being during recovery from cardiovascular disease. Health Commun. 2013;29(4):410-20. https://doi.org/10.1080/10410236.2012.762748.

19. Francis LE. Laughter, the best mediation: humor as emotion Management in Interaction. Symb Interact. 1994;17(2):147-63. https://doi.org/10.1525/si. 1994.17.2.147

20. Meyer NA, Helle AC, Tucker RP, Lengel GJ, DeShong HL, Wingate LR, Mullins-Sweatt SN. Humor styles moderate borderline personality traits and suicide ideation. Psychiatry Res. 2017;249:337-42. https://doi.org/10.1016/j. psychres.2017.01.038.

21. Martin RA, Lefcourt HM. Sense of humor as a moderator of the relation between stressors and moods. J Pers Soc Psychol. 1983;45(6):1313-24. https://doi.org/10.1037/0022-3514.45.6.1313.

22. Rnic K, Dozois DJA, Martin RA. Cognitive distortions, humor styles, and depression. Eur J Psychol. 2016;12(3):348-62. https://doi.org/10.5964/ejop. v12i3.1118.

23. Abel MH. Humor, stress, and coping strategies. Humor. 2002;15(4):365-81. https://doi.org/10.1515/humr.15.4.365.

24. Jovanovic $V$. Do humor styles matter in the relationship between personality and subjective well-being? Scand J Psychol. 2011;52(5):502-7. https://doi.org/10.1111/j.1467-9450.2011.00898.x.

25. Martin RA, Puhlik-Doris P, Larsen G, Gray J, Weir K. Individual differences in uses of humor and their relation to psychological well-being: development of the humor styles questionnaire. J Res Pers. 2003;37(1):48-75. https://doi. org/10.1016/s0092-6566(02)00534-2.

26. Erickson SJ, Feldstein SW. Adolescent humor and its relationship to coping, defense strategies, psychological distress, and well-being. Child Psychiatry Hum Dev. 2006:37(3):255-71. https://doi.org/10.1007/s10578-006-0034-5.

27. Dozois DJA, Martin RA, Bieling PJ. Early maladaptive schemas and adaptive/ maladaptive styles of humor. Cogn Ther Res. 2008;33(6):585-96. https://doi. org/10.1007/s10608-008-9223-9.

28. Schneider M, Voracek M, Tran US. "A joke a day keeps the doctor away?" meta-analytical evidence of differential associations of habitual humor styles with mental health. Scand J Psychol. 2018;59(3):289-300. https://doi.org/10. $1111 /$ sjop.12432.

29. Sareen J, Houlahan T, Cox BJ, et al. Anxiety disorders associated with suicidal ideation and suicide attempts in the National Comorbidity Survey[J]. J Nerv Ment Dis. 2005;193(7):450-4. https://doi.org/10.1097/01.nmd. $0000168263.89652 .6 b$.

30. Rasmussen KA, Wingate LRR. The role of optimism in the interpersonalpsychological theory of suicidal behavior [J]. Suicide Life-Threatening Behav. 2011;41(2):137-48. https://doi.org/10.1111/j.1943-278x.2011.00022.x.

31. Chiang YC, Yen LL, Wu WC, Chiu YC, Cheng CC, Sheng HS. Development and compilation of Taiwan adolescent humor instruments (TAHI). Psychological Testing. 2011;58:179-205. [in Chinese].

32. Chiang YC, Lee CY, Wang HH. Effects of classroom humor climate and acceptance of humor messages on adolescents' expressions of humor. Child Youth Care Forum. 2016;45(4):543-69. https://doi.org/10.1007/s10566-015-9345-7.

33. Konick LC, Gutierrez PM. Testing a model of suicide ideation in college students. Suicide Life Threat Behav. 2005;35(2):181-92. https://doi.org/10 1521/suli.35.2.181.62875.

34. Rogers ML, Stanley $\mathrm{H}$, Hom MA, Chiurliza B, Podlogar MC, Joiner TE. Conceptual and empirical scrutiny of Covarying depression out of suicidal ideation. Assessment. 2016;25(2):159-72. https://doi.org/10.1177/ 1073191116645907.

35. Eaddy M, Zullo L, Horton SE, Hughes JL, Kennard B, Diederich A, et al. A theory-driven investigation of the association between emotion Dysregulation and suicide risk in a clinical adolescent sample. Suicide Life Threat Behav. 2018;49(4):928-40. https://doi.org/10.1111/sltb.12472.

36. Don Richardson J, King L, St Cyr K, Shnaider P, Roth ML, Ketcheson F, et al. Depression and the relationship between sleep disturbances, nightmares, and suicidal ideation in treatment-seeking Canadian Armed Forces members and veterans. BMC Psychiatry. 2018;18(1):204. https://doi.org/10. 1186/s12888-018-1782-Z

37. Valois RF, Zullig KJ, Hunter AA. Association between adolescent suicide ideation, suicide attempts and emotional self-efficacy. J Child Fam Stud. 2013;24(2):237-48. https://doi.org/10.1007/s10826-013-9829-8.

38. Chioqueta AP, Stiles TC. Personality traits and the development of depression, hopelessness, and suicide ideation. Personal Individ Differ. 2005; 38(6):1283-91. https://doi.org/10.1016/j.paid.2004.08.010.

39. Pressman SD, Cohen S. Positive emotion word uses and longevity in famous deceased psychologists. Health Psychol. 2012;31(3):297-305.

40. Roberts RE, Chen YW. Depressive symptoms and suicidal ideation among Mexican-origin and Anglo adolescents. J Am Acad Child Adolesc Psychiatry. 1995;34(1):81-90. https://doi.org/10.1097/00004583-199501000-00018.

41. Brown GK, Ten Have T, Henriques GR, Xie SX, Hollander JE, Beck AT. Cognitive therapy for the prevention of suicide attempts - a randomized controlled trial. JAMA. 2005:294(5):563-70. https://doi.org/10.1001/jama.294. 5.563 .

42. Szanto K, Mulsant BH, Houck PR, Miller MD, Mazumdar S, Reynolds CF. Treatment outcome in suicidal vs. non-suicidal elderly patients. Am J Geriatr Psychiatry. 2001;9(3):261-8. https://doi.org/10.1097/00019442-20010800000010.

43. Hirsch JK, Conner KR, Duberstein PR. Optimism and suicide ideation among young adult college students. Arch Suicide Res. 2007;11(2):177-85. https:// doi.org/10.1080/13811110701249988.

44. Kovacs M. Rating scales to assess depression in school-aged children. Acta Paedopsychiatrica. 1981;46(5-6):305-15.

45. Faulstich ME, Carey MP, Ruggiero L, Enyart P, Gresham F. Assessment of depression in childhood and adolescence: an evaluation of the Center for Epidemiological Studies Depression Scale for children (CES-DC). Am J Psychiatr. 1986;143(8):1024-7. https://doi.org/10.1176/ajp.143.8.1024.

46. Watson D, Clark LA, Tellegen A. Development and validation of brief measures of positive and negative affect: the PANAS scales. J Pers Soc Psychol. 1988;54(6):1063-70. https://doi.org/10.1037/0022-3514.54.6.1063.

47. He D, Shi M, Yi F. Mediating effects of affect and loneliness on the relationship between core self-evaluation and life satisfaction among two groups of Chinese adolescents [J]. Soc Indic Res. 2014;119(2):747-56. https:// doi.org/10.1007/s11205-013-0508-3.

48. Liu D, Zhang Z, Wang M. Mono-level and multilevel mediated moderation and moderated mediation. In: Chen X, Tsui A, Farh I, editors. Empirical methods in organization and management research. 2nd ed. Beijing: Peking University Press; 2012

49. Preacher KJ, Selig, JP. Advantages of Monte Carlo confidence intervals for indirect effects. Commun Methods Meas. 2012;6(2):77-98.

50. Frewen PA, Brinker J, Martin RA, Dozois DJA. Humor styles and personalityvulnerability to depression. Humor. 2008;21(2):179-95. https://doi.org/10. 1515/humor.2008.009.

51. Tucker RP, Judah MR, O'Keefe VM, Mills AC, Lechner W, Davidson CL, et al. Humor styles impact the relationship between symptoms of social anxiety and depression. Personal Individ Differ. 2013;55(7):823-7. https://doi.org/10. 1016/j.paid.2013.07.008.

52. Wang XL. A study of American black humor novels. Shanghai: Shanghai Foreign Language Education Press; 2006. [in Chinese].

53. Mio JS. Metaphor and politics. Metaphor Symb. 1997;12(2):113-33. https:// doi.org/10.1207/s15327868ms1202_2.

54. Clouse RW, Spurgeon KL. Corporate analysis of humor. Psychology. 1995; 32(3/4):1-24.

55. Wicker FW, Barron WL III, Willis AC. Disparagement humor: dispositions and resolutions. J Pers Soc Psychol. 1980;39(4):701-9.

56. Kuiper NA, Martin RA. Humor and self-concept. Humor. 1993;6(3):251-70.

57. Jeon G-S, Ha Y, Choi E. Effects of objective and subjective socioeconomic status on self-rated health, depressive symptoms, and suicidal ideation in adolescents. Child Ind Res. 2013;6(3):479-92.

58. Zullig KJ, Pun S, Patton JM, Ubbes VA. Reliability of the 2005 middle school youth risk behavior survey. J Adolesc Health. 2000;39(6):856-60.

59. Chiang YC, Lee $\mathrm{SH}$, Yen LL, et al. Influence of stressors and possible pathways of onset of seventh graders' suicidal ideation in urban and rural areas in Taiwan[J]. BMC Public Health. 2013:13(1):1233.

60. Singer JB, Erbacher TA, Rosen P. School-based suicide prevention: a framework for evidence-based practice. Sch Ment Heal. 2018;11(1):54-7. https://doi.org/10.1007/s12310-018-9245-8. 
61. Nikrahan GR, Laferton JAC, Asgari K, Kalantari M, Abedi MR, Etesampour A, et al. Effects of positive psychology interventions on risk biomarkers in coronary patients: a randomized, wait-list controlled pilot trial. Psychosomatics. 2016; 57(4):359-68. https://doi.org/10.1016/j.psym.2016.02.007.

62. Bolier L, Haverman M, Westerhof GJ, Riper H, Smit F, Bohlmeijer E. Positive psychology interventions: a meta-analysis of randomized controlled studies. BMC Public Health. 2013;13(1). https://doi.org/10.1186/1471-2458-13-119.

63. Peters ML, Smeets E, Feijge M, van Breukelen G, Andersson G, Buhrman M, Linton SJ. Happy despite pain. Clin J Pain. 2017;33(11):962-75. https://doi. org/10.1097/ajp.0000000000000494

\section{Publisher's Note}

Springer Nature remains neutral with regard to jurisdictional claims in published maps and institutional affiliations.

Ready to submit your research? Choose BMC and benefit from:

- fast, convenient online submission

- thorough peer review by experienced researchers in your field

- rapid publication on acceptance

- support for research data, including large and complex data types

- gold Open Access which fosters wider collaboration and increased citations

- maximum visibility for your research: over $100 \mathrm{M}$ website views per year

At $B M C$, research is always in progress.

Learn more biomedcentral.com/submissions 